\title{
Differences in water mass geometry in the Atlantic Ocean during the Holocene and the last interglacial period
}

\author{
JULIA GOTTSCHALK ${ }^{1}$, FRERK PÖPPELMEIER ${ }^{2}$, \\ PATRICK BLASER ${ }^{3,4}$, DR. MARCUS GUTJAHR ${ }^{5}$, SOPHIA \\ K.V. HINES $^{6}$, LUKE C. SKINNER ${ }^{7}$, CLAIRE \\ WAELBROECK ${ }^{8}$ AND JÖRG LIPPOLD ${ }^{3}$ \\ ${ }^{1}$ Kiel University \\ ${ }^{2}$ University of Bern \\ ${ }^{3}$ Heidelberg University \\ ${ }^{4}$ University of Lausanne \\ ${ }^{5}$ GEOMAR Helmholtz Centre for Ocean Research Kiel \\ ${ }^{6}$ Woods Hole Oceanographic Institution \\ ${ }^{7}$ University of Cambridge \\ ${ }^{8}$ Université Pierre et Marie Curie, Institut Pierre Simon Laplace \\ Presenting Author: julia.gottschalk@ifg.uni-kiel.de
}

Transitions between glacial and interglacial climate periods in Earth's history manifest the role of internal climate feedbacks amplifying and modifying external climate forcing parameters. The two most recent interglacial periods, the Holocene and the last peak interglacial -Marine Isotope Stage (MIS) 5e - were shown to follow glacial states that were characterized by differences in global ice sheet extent, and the timing and pattern of ice sheet disintegration during the subsequent deglaciation. This in turn was shown to have resulted in differences in surface circulation and overturning in the North Atlantic during the Holocene and MIS5e, but associated effects on global ocean circulation patterns remain to be unraveled. Here, we compile neodymium isotope $(\varepsilon \mathrm{Nd})$ records from marine sediment cores from the Atlantic Ocean covering the last two deglacial transitions and subsequent interglacial periods, in order to elucidate differences in past water mass geometry in the Atlantic Ocean, in particular of mixing of northern and southern component waters. We expand existing datasets with new and high-resolution bulk sedimentary authigenic $\varepsilon \mathrm{Nd}$ analyses from the central South Atlantic sediment core MD07-3077 (44 $9.20^{\prime} \mathrm{S}$, $14^{\circ} 13.69^{\prime} \mathrm{W} ; 3776 \mathrm{~m}$ water depth) for Termination II and MIS5e. We observe a striking difference in mean interglacial $\varepsilon N d$ values between the Holocene (i.e., the last $10 \mathrm{kyr}$ ) and MIS5e (130-118 kyr before present) throughout the Atlantic Ocean of up to 1.5 epsilon units, with more radiogenic $\varepsilon \mathrm{Nd}$ signatures observed during MIS5e. This may reflect an overall stronger influence of southern-component waters and/or a stronger contribution of Pacific waters to the Atlantic Ocean during MIS5e compared to the Holocene, and/or endmember shifts in $\varepsilon \mathrm{Nd}$ signatures of either or all of these water masses. Assuming minor endmember shifts, our data suggest wide-spread differences in the water mass geometry of the Atlantic basin during the two most recent interglacial periods. We discuss possible mechanisms driving these differences, including a stronger retreat of the Greenland ice sheet and an associated suppression of the formation of northern-component water during MIS5e compared to the 